\title{
Most common HLA alleles associated with risk and/or protection in chronic kidney disease of undetermined etiology
}

\author{
Juan Carlos H Hernández-Rivera, ${ }^{1 *}$ Mariana Salazar-Mendoza, ${ }^{2}$ María Juana Pérez-López, ${ }^{3}$ \\ Jaime González-Ramos, ${ }^{4}$ Ramón Espinoza-Pérez, ${ }^{5}$ Julio César Martínez-Álvarez, ${ }^{6}$ Miguel Trejo-Villeda ${ }^{1}$ \\ and Ramón Paniagua-Sierra ${ }^{1}$

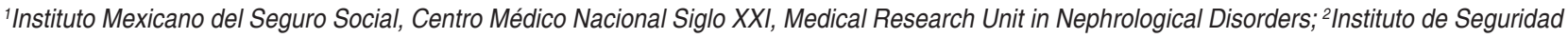 \\ y Servicios Sociales de los Trabajadores del Estado, Hospital Regional "Lic. Adolfo López Mateos", Emergency Department; ${ }^{3}$ Instituto Mexicano \\ del Seguro Social, Centro Médico Nacional La Raza, Nephrology Department; ${ }^{4}$ Instituto Mexicano del Seguro Social, Centro Médico Nacional La \\ Raza, Histocompatibility Laboratory; ${ }^{5}$ Instituto Mexicano del Seguro Social, Centro Médico Nacional Siglo XXI, Kidney Transplant Unit; ${ }^{6}$ Instituto \\ Mexicano del Seguro Social, Centro Médico Nacional Siglo XXI, Histocompatibility Laboratory, Ciudad de México, México
}

\begin{abstract}
Introduction: Chronic kidney disease accounts for part of overall health expenditure; a potential etiology is related to variations, absence or presence of some human leukocyte antigen (HLA) alleles. Method: An analysis of HLA reports of 1965 kidney recipients with no determined etiology, and 1,361 kidney donors was performed. It was carried out with Luminex based in cell flow fluorometry for the $A, B, D R B 1$ and DQA loci. An analysis was performed with contingency tables in order to determine the odds ratio (OR) and confidence intervals (Cl). Quantitative analysis was also carried out. Results: Of the 101 alleles found, 13 showed association, 7 with risk for chronic kidney disease, with the most significant being HLA-DR17 with an OR of $3.91(95 \% \mathrm{Cl}=2.96-5.17)$ and the one with the highest significance for protection being HLA-DR9, with an OR of 0.043 (95 $\% \mathrm{Cl}=0.005-0.3224)$. Conclusions: It is necessary to understand that kidney diseases can be associated with yet unknown immune processes, where the association of the absence or presence of any allele should be known.
\end{abstract}

KEY WORDS: Chronic kidney disease. Human leukocyte antigen. Kidney recipients. Alleles.

\section{Introduction}

The incidence and prevalence of chronic kidney disease (CKD) have significantly grown due to the increase in chronic degenerative diseases such as diabetes mellitus, hypertension, obesity and renal lithiasis. ${ }^{1}$ In Mexico, primary and secondary glomerulopathies cause $12.7 \%$ of $\mathrm{CKD} ;^{2}$ a significant proportion of them has an autoimmune component and, in others, the basic aspects of their pathophysiology have not yet been elucidated. In our country, it is important to know CKD epidemiology, whose cause is not established up to $50 \%$ of non-diabetic patients who are started on any dialysis treatment. ${ }^{3}$
A significant number of kidney diseases or systemic diseases with renal involvement (without considering diabetes) has genetic-immune components associated with major histocompatibility complex polymorphisms, specifically with human leucocyte antigen (HLA) molecules, which are involved in the regulation of immune processes such as antigen recognition, development of immune tolerance, cell communication, generation of cytokines on response to antigens and factors associated with inflammation and cell damage. ${ }^{4}$ Numerous currently-known HLA-disease associations do not involve a direct link with the gene allele, but with a bond imbalance, because an allele is usually tightly bound to another belonging to the locus that really has a causal relationship with the disease. ${ }^{5}$
Correspondence:

*Juan Carlos H Hernández-River

E-mail: juancarloshhernandezrivera@hotmail.com
Date of reception: 28-01-2019

Date of acceptance: 21-02-2019

DOI: 10.24875/GMM.M19000265
Gac Med Mex. 2019;155:223-227

Contents available at PubMed www.gacetamedicademexico.com 
There are well-known examples of diseases associated with HLA, such as ankylosing spondylitis (with HLA-B27), ${ }^{6}$ dermatitis herpetiformis (with HLA-A1) or associated psoriasis (with HLA-B13 and HLA-B17). ${ }^{7}$ Studies on HLA relationships with diseases face three important problems:

- Alleles associated with a disease are also found in normal population.

- A single allele can be associated with more than one disease.

- In $100 \%$ of cases of the same disease there is no association with a single allele, because allele subtypes or epitopes determine the susceptibility to suffer from it. ${ }^{8}$

On the other hand, the association is not always positive; for example, paucibacillary leprosy is less frequently related to HLA-DQ04. ${ }^{9}$

Regarding kidney diseases due to genetic disorders, idiopathic membranous glomerulopathy is linked to M-type phospholipase A2 $\mathrm{R}$ receptor, to $\lg \mathrm{G} 1$ and IgG3 glomerular deposits ${ }^{10}$ and to HLA-DR3 and DR23, with a relative risk of $12.0 .^{11}$ Other alleles, such as HLA-B18, are related to an increased risk for developing membranous glomerulopathy. ${ }^{12}$ Post-streptococcal glomerulonephritis has been associated with HLADRw4 ${ }^{13}$ HLA-DPA1*02:22, HLA-DPB $1^{*} 05: 01^{14}$ and HLA-DRB1*03:11. ${ }^{15}$ In anti- glomerular basement membrane glomerulonephritis, the related $\mathrm{HLA}$ is DR2, in association with $\mathrm{DRB} 1^{*} 15: 01^{16}$ and $\mathrm{DQB}^{*} 06: 02 .^{17-20}$

In Mexico, there is no registry available of patients with CKD or a mechanism for timely referral to the nephrologist, and the causes, stratified by demographic factors such as age, gender or ethnic characteristics, are therefore unknown. Despite the above, inferring the importance of genetic-immunological factors in the CKD epidemic is possible by means of HLA typing in patients admitted to a renal transplant program. HLA is a basic study in the selection of the recipient-donor binomial, particularly in living donors, with the purpose to choose those with the highest compatibility and with the lowest risk of rejection.

The purpose of this study is to analyze the potential association between end-stage CKD and the alleles identified in HLA tests collected during the selection of donor-recipient binomials in kidney transplant programs.

\section{Method}

A retrospective cohort from two transplant centers was analyzed between January 1, 2010 and December 31, 2017.
$\mathrm{HLA}$ reports of potential kidney transplant recipients and their potential donors were analyzed. The criteria for recipients were those established by the local committee of each transplant center. Patients with diabetic nephropathy as a cause of CKD were excluded, as well as those without complete HLA information at the time of data capture.

The reports were obtained from medical records. HLA typing was carried out with Luminex technology based on cell flow fluorimetry, using microspheres coated with purified HLA antigens at loci A, B, DRB1 and DQA; as a typing method, sequence-specific oligonucleotide primed polymerase chain reaction (PCRSSO) was used. Data were expressed as frequencies. With the information of all four loci, the frequency of each one was compared and relative risk was obtained by means of $2 \times 2$ contingency tables, with estimation of their odds ratio (OR) and their respective confidence interval $(\mathrm{Cl})$, to assess statistical significance. The quantitative analysis was performed using the SPSS program, version 25.

\section{Results}

The HLAs of 1,361 potential kidney donors were collected (39\% were the fathers or the mothers); the 1,965 potential kidney transplant recipients were grouped by alleles at each locus. Loci A, B, DRB1 and DQA were processed for each HLA test. Table 1 describes allele frequencies, stratified as "donors" and "recipients".

It should be noted that the most common allele in locus $A$ was 02 , present in 1,372 (34.91\%) recipients (both haplotypes were considered; therefore, there were 3,930 alleles in the recipients and 2,722 in the donors), whereas the HLA-A2 allele was present in $998(36.66 \%)$ donors. In locus B (the most polymorphic), the most common allele was 35 , both for recipients, with $830(21.11 \%)$, and for donors, with $618(22.7 \%)$. In the DRB1 locus, 04 was the most commonly identified, both in recipients and donors, with 1,338 (34.04\%) and 864 (31.74\%), respectively. Finally, in the DQA locus, the least polymorphic, the most common was 08 , with 1,395 (35.49\%) in recipients and 918 (33.72\%) in donors.

Regarding the risk alleles, seven associated with risk and six with protection against CKD were found. In total, 101 alleles were identified, distributed by locus as follows (Table 2):

- There were 28 HLA-A alleles, 20 common (present in donors and recipients), one only in donors 
Hernández-Rivera JCH, et al.: Risk and protection alleles in CKD

Table 1. Difference of alleles in 1,965 potential kidney receivers and 1,361 donors

\begin{tabular}{|c|c|c|c|c|c|c|c|c|c|c|c|c|c|c|c|}
\hline \multicolumn{4}{|c|}{ Locus A } & \multicolumn{4}{|c|}{ Locus B } & \multicolumn{4}{|c|}{ Locus DRB1 } & \multicolumn{4}{|c|}{ Locus DQA } \\
\hline \multicolumn{2}{|c|}{ Donors } & \multicolumn{2}{|c|}{ Receivers } & \multicolumn{2}{|c|}{ Donors } & \multicolumn{2}{|c|}{ Receivers } & \multicolumn{2}{|c|}{ Donors } & \multicolumn{2}{|c|}{ Receivers } & \multicolumn{2}{|c|}{ Donors } & \multicolumn{2}{|c|}{ Receivers } \\
\hline 01 & 110 & 01 & 170 & 06 & 1 & 07 & 130 & 01 & 149 & 01 & 207 & 01 & 4 & 01 & 9 \\
\hline 02 & 998 & 02 & 1372 & 07 & 99 & 08 & 105 & 03 & 36 & 03 & 47 & 02 & 258 & 02 & 393 \\
\hline 03 & 76 & 03 & 133 & 08 & 51 & 13 & 36 & 04 & 864 & 04 & 1338 & 03 & 361 & 03 & 458 \\
\hline 11 & 73 & 07 & 1 & 13 & 23 & 14 & 50 & 06 & 1 & 06 & 2 & 04 & 297 & 04 & 348 \\
\hline 19 & 1 & 08 & 1 & 14 & 44 & 15 & 106 & 07 & 166 & 07 & 214 & 05 & 241 & 05 & 351 \\
\hline 23 & 48 & 09 & 1 & 15 & 72 & 16 & 1 & 08 & 585 & 08 & 721 & 06 & 231 & 06 & 333 \\
\hline 24 & 449 & 11 & 114 & 18 & 51 & 18 & 119 & 09 & 16 & 10 & 36 & 07 & 392 & 07 & 614 \\
\hline 25 & 14 & 13 & 3 & 27 & 48 & 27 & 52 & 10 & 25 & 11 & 176 & 08 & 918 & 08 & 1395 \\
\hline 26 & 55 & 23 & 60 & 30 & 1 & 32 & 1 & 11 & 90 & 12 & 18 & 09 & 19 & 09 & 29 \\
\hline 28 & 2 & 24 & 684 & 31 & 1 & 35 & 830 & 12 & 9 & 13 & 209 & 15 & 1 & & \\
\hline 29 & 80 & 25 & 25 & 33 & 1 & 37 & 19 & 13 & 140 & 14 & 411 & & & & \\
\hline 30 & 95 & 26 & 68 & 35 & 618 & 38 & 58 & 14 & 267 & 15 & 180 & & & & \\
\hline 31 & 167 & 28 & 1 & 37 & 10 & 39 & 682 & 15 & 136 & 16 & 23 & & & & \\
\hline 32 & 40 & 29 & 105 & 38 & 41 & 40 & 102 & 16 & 152 & 17 & 324 & & & & \\
\hline 33 & 57 & 30 & 131 & 39 & 474 & 41 & 31 & 17 & 61 & 18 & 13 & & & & \\
\hline 34 & 5 & 31 & 261 & 40 & 79 & 42 & 11 & 18 & 14 & 19 & 1 & & & & \\
\hline 36 & 2 & 32 & 52 & 41 & 22 & 44 & 201 & 51 & 1 & 103 & 10 & & & & \\
\hline 66 & 10 & 33 & 82 & 42 & 11 & 45 & 52 & 53 & 1 & & & & & & \\
\hline 68 & 430 & 34 & 10 & 44 & 135 & 46 & 4 & 103 & 9 & & & & & & \\
\hline 69 & 5 & 35 & 1 & 45 & 24 & 47 & 1 & & & & & & & & \\
\hline \multirow[t]{15}{*}{74} & 5 & 36 & 7 & 47 & 1 & 48 & 136 & & & & & & & & \\
\hline & & 39 & 2 & 48 & 103 & 49 & 49 & & & & & & & & \\
\hline & & 66 & 16 & 49 & 37 & 50 & 31 & & & & & & & & \\
\hline & & 68 & 618 & 50 & 17 & 51 & 221 & & & & & & & & \\
\hline & & 69 & 2 & 51 & 153 & 52 & 103 & & & & & & & & \\
\hline & & 74 & 7 & 52 & 96 & 53 & 48 & & & & & & & & \\
\hline & & 80 & 3 & 53 & 18 & 55 & 15 & & & & & & & & \\
\hline & & & & 54 & 1 & 56 & 9 & & & & & & & & \\
\hline & & & & 55 & 11 & 57 & 32 & & & & & & & & \\
\hline & & & & 56 & 7 & 58 & 27 & & & & & & & & \\
\hline & & & & 57 & 17 & 60 & 50 & & & & & & & & \\
\hline & & & & 58 & 18 & 61 & 238 & & & & & & & & \\
\hline & & & & 59 & 1 & 62 & 192 & & & & & & & & \\
\hline & & & & 60 & 24 & 63 & 18 & & & & & & & & \\
\hline & & & & 61 & 143 & 64 & 28 & & & & & & & & \\
\hline
\end{tabular}

(Continues) 
Table 1. Difference of alleles in 1,965 potential kidney receivers and 1,361 donors (Continued)

\begin{tabular}{|c|c|c|c|c|c|c|c|c|c|}
\hline \multicolumn{2}{|c|}{ Locus A } & \multicolumn{4}{|c|}{ Locus B } & \multicolumn{2}{|c|}{ Locus DRB1 } & \multicolumn{2}{|c|}{ Locus DQA } \\
\hline Donors & Receivers & \multicolumn{2}{|c|}{ Donors } & \multicolumn{2}{|c|}{ Receivers } & Donors & Receivers & Donors & \multirow[t]{2}{*}{ Receivers } \\
\hline & & 62 & 151 & 65 & 71 & & & & \\
\hline & & 63 & 10 & 68 & 2 & & & & \\
\hline & & 64 & 11 & 69 & 1 & & & & \\
\hline & & 65 & 51 & 71 & 10 & & & & \\
\hline & & 70 & 2 & 72 & 19 & & & & \\
\hline & & 71 & 10 & 73 & 7 & & & & \\
\hline & & 72 & 11 & 75 & 7 & & & & \\
\hline & & 73 & 5 & 78 & 10 & & & & \\
\hline & & 75 & 11 & 81 & 3 & & & & \\
\hline & & 78 & 4 & 82 & 2 & & & & \\
\hline & & 81 & 3 & & & & & & \\
\hline
\end{tabular}

and seven in recipients; one with statistical significance for risk, which was allele 11.

- There were 43 HLA-B alleles, 30 common, seven only in donors and six in recipients; alleles 08 , 18 and 53 had risk significance.

- There were 20 HLA-DRB1 alleles, 16 common, three in donors and one in recipient, with significance for risk in three cases $(04,11$ and 17$)$, as well as three associated with protection (08, 09 and 16).

- There were 10 HLA-DQA alleles, nine common and one only in donors; two protective alleles against CKD (03 and 04) were identified.

Two alleles particularly drew attention: one associated with risk, HLA-DR17, with OR = 3.91 (95\% $\mathrm{Cl}=2.96-5.17)$, and one associated with protection, with high statistical weight, HLA-DR09, with $\mathrm{OR}=0.043(95 \% \mathrm{Cl}=0.005-0.3224)$.

\section{Discussion}

We were able to confirm that there are alleles associated with risk for developing kidney disease, but also with protection to reduce the possibilities of CKD; in total, 3,326 HLAs were collected (in 1,965 potential kidney transplant recipients and 1,361 potential donors). The most common alleles per locus were similar to those found in Mexico by our same working group:21 alleles 2, 35, 4 and 3, respectively, were the most common for loci $A, B, D R B 1$ and DQA.
Of the alleles associated with risk for CKD (seven), one was found in locus $A$ (11), which was specifically associated with cytomegalovirus, Epstein-Barr and autoimmune hepatitis. ${ }^{22}$ In locus $B$, three risk alleles were identified: 8 , related to lupus erythematosus and $\operatorname{IgA}$-associated nephropathy; ${ }^{23} 18$, associated with membranous glomerulopathy and systemic lupus erythematosus:13 and B17, even when in the literature search no association with any kidney disease was found. Finally, in the DRB1 locus, three risk alleles were found: allele 4, related to post-streptococcal glomerulonephritis; ${ }^{13}$ allele 11 , associated with hepatitis C (cause of membranoproliferative glomerulopathy), glomerulonephritis, Sjögren syndrome, lupus erythematosus and rheumatoid arthritis; ${ }^{24}$ and allele 17, related to lupus and cardiovascular hypertrophy. ${ }^{25,26}$

Regarding the six significant protection alleles, no studies were found that could establish a parallelism with the results of our work (Table 2).

In a large number of renal patients on transplant protocol, the etiology was not known (in more than $95 \%$ ), and thus it was difficult to assume the relationship; however, the statistical significance of risk and protection could be established for each case, specifically in 13 of the 101 alleles, seven associated with risk and six with protection, which was an information by means of which we would able to determine, although not with certainty, the potential causes in patients with these alleles and thus establish earlier diagnoses of kidney diseases and verify those associations with higher precision. 
Tabla 2. Risk and protection alleles in chronic kidney disease

\begin{tabular}{|l|r|r|r|}
\hline Locus & Allele & Odds ratio & Confidence interval \\
\hline Risk for CKD & & & \\
\hline HLA-A & 11 & 1.61 & $1.14-2.27$ \\
\hline HLA-B & 08 & 1.42 & $1.02-2.01$ \\
\hline HLA-DRB1 & 18 & 1.63 & $1.17-2.27$ \\
\hline & 53 & 1.85 & $1.07-3.20$ \\
\hline Protection against CKD & 1.11 & $1.002-1.23$ \\
\hline HLA-B & 11 & 1.37 & $1.06-1.78$ \\
\hline HLA-DRB1 & 08 & 3.91 & $2.96-5.17$ \\
\hline & 09 & 0.043 & $0.55-0.97$ \\
\hline HLA-DQA & 03 & 0.86 & $0.72-0.92$ \\
\hline & 04 & 0.79 & $0.74-0.99$ \\
\hline & 16 & 0.09 & $0.67-0.93$ \\
\hline
\end{tabular}

$\mathrm{CKD}=$ chronic kidney disease

The main limitation of the study was that it was not possible to identify the association between HLA alleles and the cause of CKD since, unfortunately, in more than $95 \%$ of patients the cause was unknown because no kidney biopsies were available due to the delay the patients sought medical attention with. Patients with diabetic nephropathy were excluded.

\section{Conclusions}

It is essential for the causes that originate CKD to be known, as a line of action to reduce morbidity and mortality associated with this entity. The immune origin should not be minimized, and neither should the presence, absence and association of alleles, both for the risk and the protection they may imply. In total, 13 alleles related to risk-protection were found: seven associated with risk $(6.9 \%)$, with statistical significance, and six associated with protection (5.9\%) against the development of CKD. Two of the 13 alleles had particular statistical significance: HLA-DR17, for risk, and HLA-DR, for protection.

As for glomerulopathy, knowing the cause of CKD would allow the following:

- Improving the certainty of the HLA-glomerulopathy association, based on the histopathological result of a renal biopsy and HLA determination, as part of the tests of a potential renal receiver.

- Estimating the risks of post-transplant glomerulopathy relapse

\section{References}

1. Dehesa E. Enfermedad renal crónica; definición y clasificación. El Residente. 2008;3:73-78

2. Méndez-Durán A, Méndez-Bueno F, Tapia-Yáñez T, Muñoz-Montes A, Aguilar-Sánchez L. Epidemiología de la insuficiencia renal crónica en México. Diálisis y Trasplante. 2001;31:7-11.

3. Flores J. Enfermedad renal crónica: epidemiologia y factores de riesgo. Rev Med Clin Condes. 2010;21:502-507.

4. Jadue N, González A. Inmunopatogenia de las enfermedades autoinmunes. Rev Med Clin Las Condes. 2012;23:464-472.

5. Morera-Barrios LM, Verdura-González TE, Martínez-Legón Z, Ricardo-Lorenzo R. Asociación de antígenos HLA y enfermedades oftalmológicas. Rev Cubana Hematol Inmunol Hemoter. 2001;17:7-18.

6. Tolosa A. Primer catálogo de enfermedades asociadas con variaciones en los genes de los antígenos leucocitarios humanos. España: Genética Médica; 2017.

7. Corrales $\mathrm{P}$, Corrales A, Carias S. Asociación entre HLA y enfermedad, estado actual y perspectivas. Rev Med Hondur. 1985;53:104-118.

8. Fernández J. HLA y enfermedad. Rev Med Hondur. 1991:51:151-154.

9. Fabiana P, Cech N, Fontan C, Giménez M, Lodeiro N, Marinic K, Molinari M, Sotelo M, Habegger A. Papel de las moléculas HLA-DR y HLA DQ en la lepra en la provincia del Chaco, Argentina. Enferm Infecc Microbiol Clin. 2007;25:627-631.

10. Nachman $P$, Jannette J Falk R. Primary glomerular disease. En: Skorecki K, Chertow GM, Marsden PA, Taal MW. Brenner \& Rector's. The Kidney. EE. UU.: Elsevier; 2012.

11. Klouda PT, Manos J, Acheson EJ, Dyer PA, Goldby FS, Harris R, et al. Strong association between idiopathic membranous nephropathy and HLA-DRW3. Lancet. 1979:2:770-771.

12. Dyer PA, Klouda PT, Harris R, Mallick NP. Properdin factor B alleles in patients with idiopathic membranous nephropathy. Tissue Antigens. 1980;15:505-507.

13. Layrisse Z, Rodríguez-Iturbe B, García-Ramírez R, Rodríguez A Tiwari J. Family studies of the HLA system in acute post-streptococcal glomerulonephritis. Hum Immunol. 1983;7:177-185.

14. Mori K, Sasazuki T, Kimura A, Ito Y. HLA-DP antigens and poststreptococcal acute glomerulonephritis. Acta Pediatr. 1996:85:916-918.

15. Bakr A, Mahmoud LA, Al-Chenawi F, Salah A. HLA-DRB1* alleles in Egyptian children with post-streptococcal acute glomerulonephritis. Pediatr Nephrol. 2007;22:376-379.

16. Fisher M, Pusey CD, Vaughan RW, Rees AJ. Susceptibility to anti-glomerular basement membrane disease is strongly associated with HLADRB1 genes. Kidney Int. 1997;51:222-229.

17. Huey B, McCormick K, Capper J, Ratliff C, Colombe BW, Garovoy MR, et al. Associations of HLA-DR and HLA-DQ types with anti-GBM nephritis by sequence-specific oligonucleotide probe hybridization. Kidney Int. 1993:44:307-312.

18. Dunckley H, Chapman JR, Burke J, et al. HLA-DR and -DQ genotyping in anti-GBM disease. Dis Markers. 1991;9:249-256.

19. Burns AP, Fisher M, Li P, Pusey CD, Rees AJ. Molecular analysis of HLA class II genes in Goodpasture's disease. QJM. 1995:88:93-100.

20. Kitagawa W, Imai H, Komatsuda A, Maki N, Wakui H, Hiki Y, et al. The HLA-DRB1*1501 allele is prevalent among Japanese patients with anti-glomerular basement membrane antibody-mediated disease. Nephrol Dial Transplant. 2008;23:3126-3129.

21. Hernández-Rivera JCH, González-Ramos J, Pérez-López MJ, Carmona-Becerril A, Escárcega-Vázquez A, Cruz-Santiago J, et al. The most common HLA antigens found in patients with renal transplants at the specialties hospital of "La Raza" medical center, México. Transplant Proc. 2016;48:572-574.

22. Contreras G, Lenz O, Pardo V, Borja E, Cely C, lqbal K, et al. Outcome in African Americans and Hispanics with lupus nephritis. Kidney Int. 2006;69:1846-1851

23. Appel GB, Jayne D. Lupus nephritis. En: Johnson R, Floege J, Feehaly J, editores. Comprehensive clinical nephrology. EE. UU: Elsevier; 2010.

24. Gendi NS, Welsh KI, Van-Venrooij WJ, Vancheeswaran R, Gilroy J, Black CM. HLA type as a predictor of MCTD differentiation. Ten year clinical and immunogenetic follow-up of 46 patients. Arthritis Rheum. 1995:38:259-266.

25. Diamantopoulos EJ, Andreadis EA, Vassilopoulos CV, Vlachonikolis IG, Tarassi KE, Chatzis N, et al. Association of specific HLA phenotypes with left ventricular mass and carotid intima-media thickness in hypertensives. Am J Hypertens. 2001;14:632-636.

26. Waldman M, Madaio MP. Pathogenic autoantibodies in lupus nephritis. Lupus. 2005;14:19-24 